\title{
EL PENSAMIENTO COMO SUJETO AUTONOMIZADO. REVISITANDO EL VÍNCULO ENTRE MARX Y HEGEL
}

\author{
RODRIGo STEIMBERG \\ bttps://orcid.org/0000-0002-7153-235X \\ Universidad Nacional de Quilmes \\ Consejo Nacional de Investigaciones Científicas y Técnicas \\ bttps://doi.org/10.15304/ag.40.2.6732
}

\section{Resumen}

El presente escrito se apoya en la crítica que realiza Marx a Hegel para elucidar cuáles son las determinaciones del modo de producción capitalista que permiten a este último desarrollar las formas generales del método dialéctico. Afirmamos que, dado que el capital goza de un movimiento automático, a Hegel se le presenta que la conciencia, que realiza dicho movimiento, se pone en marcha a sí misma. Pese a esto, siguiendo a Marx, sostenemos que Hegel explica la estructura básica del método dialéctico, el afirmarse mediante la propia negación de toda forma real.

Palabras clave: dialéctica, capital, sujeto, inversión, libertad.

\begin{abstract}
The approach introduced in this paper bases on Marx's criticism of Hegel in order to explain which determinations of capitalism allow Hegel to describe the general forms of the dialectical method. We affirm that, since capital has an automatic movement, Hegel supposes that the conscience, which realizes this movement, sets itself in motion. Nevertheless, following Marx we argue that Hegel clarifies the basic structure of the dialectical method, i. e., the affirmation through self-negation of every real form.

Keywords: dialectics, capital, subject, inversion, freedom.
\end{abstract}

Recibido: 13/04/2020. Aceptado: 30/06/2020. 


\section{Introducción}

El presente escrito pretende dar cuenta de la historicidad del conocimiento dialéctico a partir de la crítica que realiza Marx a Hegel. Interroga cuáles son las determinaciones del modo de producción capitalista que enfrentan a Hegel a describir las formas generales del método dialéctico. Sobre esta base, intenta exponer las causas por las que, en palabras de Marx, se trata de una propuesta que encierra un núcleo racional y una envoltura mística.

A estos fines, describiremos en primer lugar las determinaciones generales de la organización del trabajo social por la mercancía. En segundo lugar, mostraremos la crítica que realiza Hegel a la libertad formal. Por último, expondremos las determinaciones del capital que explican por qué Hegel autonomiza la conciencia de sus determinaciones por el ser social, para fundamentar, así, qué toma Marx por núcleo racional de su dialéctica y qué como su envoltura mística. Afirmaremos que, dado que el capital goza de un movimiento automático, a Hegel se le presenta que la conciencia, que es la encargada de realizar dicho movimiento, se pone en marcha a sí misma. En otras palabras, que Hegel reproduce en el terreno del pensamiento el movimiento real del capital como si éste se tratase de un movimiento de la conciencia autonomizada de sus determinaciones materiales. Lo cual nos permitirá sostener que el filósofo alemán da cuenta de la forma central del método dialéctico, el afirmarse mediante la propia negación de toda forma real, a la vez que pierde de vista la determinación histórica en juego que explica el desarrollo de la dialéctica bajo el modo de producción capitalista.

\section{El vínculo de Marx con Hegel. El núcleo racional de la dialéctica hegeliana}

La cuestión del vínculo entre Marx y Hegel ha sido objeto de debate en el campo marxista desde sus inicios. Recientemente, y de la mano de un conjunto de pensadores que han puesto el foco en el aspecto metodológico de la crítica de la economía política desarrollada por Marx (Smith, 1990; Murray, 1993; Moseley \& Campbell, 1997; Arthur, 2004; Albritton \& Simoulidis, 2003; Robles Baez, 2005; Moseley \& Smith, 2014), esta cuestión ha recobrado vitalidad como objeto de discusión. El presente trabajo pretende insertarse en este campo general de estudios.

Los autores enmarcados en el enfoque conocido como Dialéctica Sistemática (Robles Baez, 2004: 14) acentúan el desenvolvimiento dialéctico de las categorías de la crítica marxiana de la economía política y enfatizan, 
así, su relación con la Ciencia de la Lógica de Hegel ${ }^{1}$. Aquí nos limitaremos a revisitar los trazos fundamentales de los planteamientos de Christopher Arthur y de Tony Smith, en tanto constituyen las dos figuras que concentran las principales líneas interpretativas que confluyen en la Dialéctica Sistemática (Robles Báez, 2005: 14).

Entre la multiplicidad de autores que abordan las relaciones entre Marx y Hegel, enfocamos nuestro trabajo en los aportes de la Dialéctica Sistemática porque consideramos que en ellos se reúnen los desarrollos más agudos y exhaustivos sobre el punto que concita nuestra atención: la discriminación del núcleo racional de la dialéctica, el aspecto que constituye un aporte de Hegel para el enfoque de Marx, de su envoltura mística, aquella dimensión de la filosofía hegeliana que transforma a su dialéctica en una idealista.

Tony Smith rechaza que la filosofía de Hegel encierre un carácter idealista. La tarea de la filosofía, de acuerdo a su perspectiva, consiste en apropiarse de las categorías que utilizamos acríticamente en nuestra experiencia. Hegel, como expresión más acabada de esta empresa, despliega las categorías involucradas en el conocimiento del mundo y desarrolla dialécticamente su trabazón interna, que las impulsa a alcanzar mayores niveles de complejidad y concreción (Smith, 1990: 5). Para Smith, la filosofía de Hegel no sería idealista por reducir del mundo material a categorías del pensamiento. Tampoco afirmaría que la dialéctica de las categorías es idéntica a la que opera en la totalidad de lo real, sino que, nuevamente, se limitaría a reconstruir sus determinaciones fundamentales (1990: 14). Es decir, Hegel no haría del mundo material la reproducción idéntica del ideal, ni buscaría reducir el primero al segundo. Justamente por esto, Smith sostiene que Marx toma de Hegel la dialéctica, toda vez que el primero procede tomando a ciertas categorías, las más abstractas, como aquellas que por su propio desenvolvimiento permiten pensar la concreción y complejidad de lo real. Es decir, que según Smith Marx toma a toda determinación como una forma desplegada de su estructura interna, comprensible solamente si se la conceptualiza mediada por las categorías más generales (1990: 14). El énfasis en las relaciones y en la necesidad de un ordenamiento categorial de los fenómenos emparentaría, así, al método de Marx con el de Hegel.

\footnotetext{
${ }^{1}$ Para un análisis pormenorizado de las principales líneas de la Dialéctica Sistemática, Starosta, 2017. Pueden consultarse las siguientes obras, que consideramos troncales dentro del enfoque: Fineschi, 2009; Bellofiore, 2014; Murray, 1993; Arthur y Reuten, 1998; Moseley, 2005.
} 
La teoría de Christopher Arthur resume la otra vertiente central de la Dialéctica Sistemática. Arthur sostiene que existe una homología entre la estructura de la Ciencia de la Lógica hegeliana y El Capital marxiano (Arthur, 2004: 7). Esta homología — parcial desde nuestro punto de vistaresponde a que el capital es un proto-sujeto, que para mostrarse como tal debe producir sus propias condiciones de existencia (Arthur, 2005, p. 251). En este tránsito, debe lidiar con un sujeto que a la vez es puesto por él mismo: el proletariado. Este otro interno, cuya fuerza el capital debe doblegar y convertir en un mero accesorio (Arthur, 2005, p. 251), tiene la capacidad potencial de revolucionarlo. Por lo cual, para probarse como forma absoluta, debe subordinar la realidad material del trabajo y producirla, así, como su propio presupuesto. Recién allí el capital deviene realmente lo que era como forma en su figura general (Arthur, 2004, pp. 10-11 y 52-53). Aquí es donde Arthur introduce el paralelismo entre el capital y la Idea hegeliana. Ambos deben sumergirse en el mundo de la otredad para comprobar que son sujetos en el sentido pleno; uno frente al trabajo vivo, el otro frente a la Naturaleza. Así como el capital debe subordinar el mundo de la producción, en el que debe probarse como sujeto absoluto apropiándose del trabajo del proletariado, requisito de lo cual es doblegarlo en la lucha de clases, así el Concepto debe separarse de sí en la Naturaleza, para conformarla a su imagen y semejanza (Arthur, 2005, p. 255). Pero aquí es donde Arthur funda, también, la diferencia entre la dialéctica materialista y la hegeliana. Mientras que la Idea detenta la capacidad para subsistir en sí, para fundarse, el capital puede no hacerlo (Arthur, 2005: 253). Con lo cual, mientras que la Idea es capaz de manifestarse en la Naturaleza, penetrando en ella y retornando a su seno, el capital debe, para eso, derrotar a la clase obrera para ponerla como su propio presupuesto, mediando este proceso la lucha de clases.

La tesis de la homología entre el movimiento del capital y el de la Idea Absoluta, como el mismo Arthur desliza (Arthur, 2005: 255), encuentra sus rudimentos en el trabajo de Lucio Colletti (1975). De cara a nuestros intereses, esto es, la fundamentación de la separación de un núcleo racional y una envoltura mística en la filosofía hegeliana, —siguiendo el adagio marxiano (Marx, 1999: 20)—Colletti resulta un autor central, en tanto el filósofo italiano impugna justamente la posibilidad de dicha separación (Caligaris y Starosta, 33).

Colletti señala que la dialéctica constituye una propuesta que refleja la realidad invertida de un objeto en particular: el capital. En este sentido, parafraseando a Marx, para este autor la dialéctica resulta la lógica peculiar 
de un objeto peculiar. La relación social enajenada, que se pone en marcha a sí misma con el objeto de aumentar su propia magnitud responde, según Colletti, a la lógica del Absoluto hegeliano, en la cual toda determinación finita es la forma en la que se realiza un infinito que existe para sí mismo. Es decir, el capital, en tanto relación social enajenada se ajusta al movimiento del universal absoluto hegeliano que, en vez de ser un predicado de lo concreto, transforma a este concreto en su propia manifestación y deviniene así un sujeto que existe más allá de él, una entidad autosubsistente (Colletti, 1975: 169-171).

Colletti afirma que este movimiento dialéctico que refleja la inversión propia del capital es en sí mismo idealista. El carácter autocontradictorio de lo finito, destacado por Hegel en el segundo capítulo de la Ciencia de la Lógica, implica que toda entidad finita, esto es, el mundo material, engendra por sí mismo a su contrario, lo infinito. Se muestra entonces como una de sus formas de existencia. Como lo infinito universal es para Hegel el pensamiento, según Colletti la dialéctica posee en sí misma un carácter idealista ya que hace del mundo material un predicado de lo Absoluto, concebido como pensamiento (Colletti, 1975: 77-78). De este modo, Colletti señala que la dialéctica hegeliana es la lógica concreta de un objeto concreto en sí mismo invertido, transformado en autónomo ideal ${ }^{2}$. Por lo cual, por ser la expresión de este objeto invertido, no puede sino ser un método enajenado, idealista (Colletti, 1975: 175). Para Colletti entonces, un método compatible con los procedimientos científicos debe anclarse en el concepto kantiano de oposición real y no en el de contradicción dialéctica, que considera desprovisto de sentido (Colletti, 1982: 120).

Ofreceremos una línea argumentativa que se opone a aquella de la que Tony Smith es exponente ${ }^{3}$, en tanto diremos que es posible encontrar un aspecto mistificado en la dialéctica de Hegel. Smith, al realizar una lectura materialista de Hegel, socava esta alternativa y encuentra una robusta línea de continuidad metodológica con Marx (1990: 8). De ahí que el propio señalamiento de un carácter idealista en la dialéctica hegeliana supone tomar distancia de su enfoque. Rescataremos del planteamiento de Arthur, que continúa el de Colletti, el énfasis en la forma de movimiento propia del capital —su operatoria como sujeto- a la hora de explicar la envoltura

${ }^{2}$ De aquí que Colletti resulte una apoyatura central para la tesis de la homología sostenida por Arthur.

${ }^{3}$ Siguiendo a Bellofiore, ubicamos en esta línea el desarrollo de Reuten (Bellofiore, 2014; Reuten \& Williams, 1989). 
mística que recorre a la dialéctica de Hegel. Así, intentaremos argumentar que la dialéctica se ajusta al movimiento material del capital, y que es este mismo movimiento el que explica por qué Hegel lo presenta de forma idealista. Sin embargo, este punto supone tomar distancia del análisis de Arthur, en tanto para él la tesis de la homología se rompe allí donde Marx insiste en que el capital debe doblegar la resistencia de la clase obrera para erigirse como sujeto pleno (Arthur, 2005, 251), mientras que Hegel expone un movimiento plenamente circular, en el que lo Absoluto pone sus propias condiciones (2005: 254). Marx, así, se separaría de Hegel al sostener que la ontología social propia del capital no se ajustaría al movimiento de la Idea Absoluta, en tanto la última garantiza su capacidad para producir sus presupuestos, mientras que el primero, el capital, tiene comprueba esta condición al doblegar a la clase obrera (2005: 251 y ss.). De modo que la fertilidad científica y metodológica que la filosofía de Hegel tendría para la crítica marxiana se detendría allí donde Hegel impondría un movimiento plenamente circular al sujeto de la dialéctica, condición que el capital no cumple necesariamente. Allí residiría, entonces, la differentia specífica de Marx frente a Hegel y el límite propio de la filosofía hegeliana como tal.

A partir de los desarrollos de Juan Iñigo Carrera (2004; 2007; 2012), para nosotros, en cambio, la cuestión pasa por elucidar por qué este modo de organizar el trabajo produce entre sus formas de conciencia a la dialéctica, así como de dar cuenta, en el terreno de las determinaciones generales del capital, de la necesidad de que Hegel lo exponga de forma idealista. El terreno en el que ubicamos el vínculo entre Marx y Hegel nos aparta, entonces, del señalamiento de Arthur. Esto obedece a que, en oposición a su teoría, procuraremos mostrar que la diferencia entre los planteamientos de Marx y de Hegel tiene lugar justamente porque el capital es el sujeto de la vida social, no a pesar de ello (Robles Báez, 2011: 65-66; Postone, 2006: 91, 93; Iñigo Carrera, 2004: 80). Comencemos entonces con este desarrollo.

\section{La conciencia del individuo doblemente libre}

Para preguntarnos por el vínculo entre el desarrollo del modo de producción y el del conocimiento dialéctico, debemos, primero, comenzar por precisar qué entenderemos, siguiendo a Iñigo Carrera, por conciencia.

En cualquier fase de la historia, los seres humanos necesitan organizar cómo aplicarán los trabajos útiles concretos que reclama la reproducción de la sociedad. Toda sociedad humana necesita producirse a sí misma, 
requisito de lo cual es la organización de la aplicación del trabajo necesario para ello. Esta organización está portada en un conjunto de relaciones sociales (Marx y Engels, 1976: 16; Iñigo Carrera, 2004: 2). Tomaremos a la conciencia como la forma concreta que tiene cada individuo de organizar su participación en este proceso. Es decir, como la capacidad que tiene el sujeto humano individual para organizar su trabajo. No resulta, de este modo, un atributo ajeno a la acción genérica humana de transformación del medio en uno para sí. Por el contrario, se trata de la fase de la acción cuya determinación es precisamente la organización de la acción misma. Tal como lo presentan Marx y Engels, "La conciencia no puede ser nunca otra cosa que el ser consciente, y el ser de los hombres es su proceso de vida real" (Marx y Engels, 1970: 26). Como la organización de la descarga de las cuotas de trabajo individual se encuentra portada en las conciencias igualmente individuales, esta organización carece de una existencia exterior a la conciencia. Afirmar, como hace Marx, que el ser social determina a la conciencia (Marx y Engels, 1971: 9) no implica que el ser social sea una cosa ante la cual la conciencia deba, a su vez, reaccionar, devolviéndole la determinación que de él recibe - ya sea para reproducirlo o revolucionarlo. El ser social, las relaciones sociales en las que los individuos entran para producir su propia vida, toma forma en las conciencias individuales de los seres humanos, es inmanente a ellas. Ahora bien, ¿qué distingue a la conciencia propia del individuo doblemente libre? Para respondernos a esta pregunta, debemos atender al modo en el que se encuentra organizado el trabajo social.

La mercancía es el resultado de la inexistencia de organización directa alguna con anterioridad a la aplicación de las alícuotas del trabajo social que son los trabajos individuales (Iñigo Carrera, 2012: 75). Esta carencia de unidad directa es lo que expresa el mercado como momento en el que los distintos trabajos privados prueban si formaban parte, al momento de ser realizados, del conjunto del trabajo socialmente necesario para reproducir la vida material de la humanidad. De modo tal que la mercancía es la encargada de establecer la unidad entre producción y consumo, dado que se encarga de sancionar si los trabajos privados se materializaron en valores de uso necesarios para la reproducción de la sociedad. El valor, que es el atributo social que se objetiva en el producto del trabajo, es lo que organiza la producción y el consumo de la sociedad. Dice Marx:

Si los objetos para el uso se convierten en mercancías, ello se debe únicamente a que son productos de trabajos privados ejercidos independientemente los unos de los otros. El complejo de estos trabajos privados es lo que constituye el trabajo social global. Como los productores no entran en contacto social hasta que intercambian 
los productos de su trabajo, los atributos específicamente sociales de esos trabajos privados no se manifiestan sino en el marco de dicho intercambio. $\mathrm{O}$ en otras palabras: de hecho, los trabajos privados no alcanzan realidad como partes del trabajo social en su conjunto, sino por medio de las relaciones que el intercambio establece entre los productos del trabajo y, a través de los mismos, entre los productores (Marx, 1999: 89). ${ }^{4}$

En tanto la organización del trabajo social se realiza de forma privada e independiente y, por tanto, a través de la aptitud para el cambio de los productos del trabajo, el productor de mercancías gobierna consciente y voluntariamente su proceso de trabajo individual, sin hallarse sujeto a relaciones de dependencia personal con nadie. Es decir, el productor directo organiza su trabajo individual como lo considere pertinente; en la venta de su producto se mostrará si la aplicación concreta de su cuota de trabajo social se materializó en objetos necesarios para reproducir la sociedad.

El productor de mercancías no se encuentra atado a relaciones de dependencia personal. Es libre porque está sometido a su propia relación social, porque debe producir valor para reproducirse. Domina su propio proceso individual de trabajo y, a la vez y por la misma determinación, no puede controlar sus potencias sociales, lo cual implica poner su conciencia y voluntad al servicio de la producción de valor (Iñigo Carrera, 2004: 23). Esta doble condición obedece a que en el momento en el que el individuo aplica su cuota de trabajo desconoce si se trata de un trabajo socialmente necesario. De aquí que el individuo libre se enfrente a sus relaciones sociales como algo que lo dominan y no puede controlar.

En la esfera de la circulación, el contenido del vínculo social aparece de forma invertida. En ella imperan la libertad, la igualdad y la propiedad, puesto que los compradores y vendedores de mercancías aparecen como sujetos autónomos, cuyo estatuto de personas se sanciona jurídicamente, decididos a entablar un contrato de compraventa en el que se desprenden de aquello que disponen a cambio de hacerse de la mercancía del otro (Marx, 1999: 214). El contenido de estas apariencias indica que: frente a la libertad, se levanta el carácter forzado de la venta de la fuerza de trabajo; frente a la igualdad en el intercambio de equivalentes, la explotación del obrero por el capital; frente a la propiedad, la condición de individuo doblemente libre del trabajador; frente al interés personal, la determinación de la conciencia y la voluntad por el capital social, para el cual el trabajador es uno forzado (Marx, 2006: 721-725).

\footnotetext{
${ }^{4}$ Salvo expresa aclaración, las cursivas pertenecen al original.
} 
En síntesis, la interdependencia que rige el proceso de metabolismo social bajo el modo de producción capitalista, en el cual el consumo de cada uno de los individuos depende de haber podido vender su propia mercancía - lo que lleva implícito el consumo de los otros- se presenta ante la conciencia de estos individuos, producto de su inversión en la esfera de la circulación, como brotando del ejercicio de su propia conciencia y voluntad. El hecho de que el productor de mercancías deba, para poder comportarse como persona, realizar la personificación de su mercancía, aparece ante su voluntad de forma invertida. Y, así mismo, el hecho de tener que poner su conciencia y su voluntad al servicio de la producción de valor, se presenta ante los ojos del productor de mercancías como el resultado de su carencia de vínculos sociales a la hora de poner en marcha su proceso individual de trabajo. Esto es, se presenta como su independencia, y por tanto libertad, respecto de los demás. Por eso, se enfrenta a su interdependencia social como el efecto de su independencia, como el resultado de su intercambio con los otros una vez ejercida su autonomía en el ámbito de la producción de valores de uso. $\mathrm{Y}$, así como se levanta la apariencia de que su interdependencia brota de su independencia, al productor privado se le presentan sus pares como individuos que disponen libremente de su conciencia y voluntad. De ahí que su propia libertad encuentre, para él, un límite en el ejercicio de esta misma por parte de los demás (Iñigo Carrera, 2007: 64-65). Para avanzar sobre el vínculo entre Marx y Hegel veamos entonces cómo trata este último a la libertad de la conciencia del productor de mercancías.

\section{La libertad de la conciencia en la filosofía de Hegel}

En el contexto de la filosofía de Hegel carece de sentido preguntarse por la determinación de la conciencia por el ser social. Por el contrario, la cuestión pasa por elucidar qué figura de la conciencia es la que se realiza en una cierta fase histórica. Justamente porque para Hegel la conciencia se autodetermina, se pone en marcha a sí misma o constituye el sujeto de su propio movimiento, no tiene fundamento cuestionar qué forma de organización del trabajo social la produce. Veamos esto con mayor detenimiento.

Para Hegel el principio que explica la organización de toda sociedad es una cierta figura del espíritu que en ella se realiza y que se supera en tanto la conciencia $^{5}$ experimenta la contradicción que le da lugar (Hegel, 2006: 54,

${ }^{5}$ La conciencia, como punto de partida del movimiento que Hegel acompaña hasta llegar al saber, es ya este movimiento, es esta contradicción que por su propio impulso se 
179). De hecho, Hegel culmina la Fenomenología con las siguientes palabras: "La meta, el saber absoluto o el espíritu que se sabe a sí mismo como espíritu tiene como su camino el recuerdo de los espíritus como son en ellos mismos y como llevan a cabo la organización de su reino. Su conservación vista por el lado de su ser allí libre, que se manifiesta en la forma de lo contingente, es la historia, pero vista por el lado de su organización conceptual es la ciencia del saber que se manifiesta" (Hegel, 2006: 473).

Este saber que se manifiesta es el tránsito de la conciencia, que se afirma negando sus propias determinaciones. Pero, con esta negación, Hegel no apunta a que la conciencia rechace sus determinaciones en aras de afirmar su independencia. De hecho, Hegel impugna que la libertad de la conciencia dependa de mantener un vínculo exterior con ellas. Dice en la Filosofía del Derecho:

La voluntad es la unidad de estos dos momentos: la particularidad reflejada en sí y referida, en consecuencia, a la universalidad, esto es, la individualidad; la autodeterminación del Yo de ponerse en lo Uno como negación de sí mismo, en cuanto determinado, limitado; y de quedar en sí, esto es, en la propia identidad consigo, en la propia universalidad y de unirse consigo mismo, en la determinación (...) Aquí sólo se puede hacer notar aun que cuando se dice: la voluntad es universal, la voluntad se determina, se representa la voluntad ya como sujeto presupuesto o como substrato; pero ella no es conclusión y universalidad antes de determinarse y antes de la eliminación e idealización de esa determinación, sino que es voluntad en cuanto actividad que se concilia en sí y como reversión a sí (Hegel, 2009: 47-48).

Para Hegel la voluntad no es la actividad de abstraerse de toda determinación, ni consiste en presentarse como pura posibilidad de ponerse frente a lo existente. La voluntad es darse una existencia determinada y, al mismo tiempo, permanecer y reproducirse como voluntad en esta determinación. En eso mismo, para Hegel consiste la libertad: "Pero la verdad de esta universalidad formal, indeterminada por sí, y que encuentra su determinación en aquella materia, es la universalidad que se determina a si misma, la voluntad, la libertad" (Hegel, 2009: 55). Esto quiere decir que ser libre no implica separarse de las propias determinaciones, abstraerse de ellas como si fuesen límites al albedrío de uno sobre su propia individualidad sino

enriquece. Por lo cual, es ya pensamiento, es ya puro. La conciencia, en este sentido, se pone en marcha a sí misma y deviene pensamiento. Al tratarlas como equivalentes nos referimos a que la conciencia es el punto de partida de aquello que va a devenir pensamiento y este movimiento lo realiza por su propio desenvolvimiento, por su propio carácter contradictorio. Así, pretendemos destacar que la conciencia se pone en marcha a sí misma para llegar a ser lo que es, cuando si se tomara por objeto el recorrido realizado por Hegel para mostrar este tránsito sería menester detenerse en sus distintas fases. 
que, por el contrario, supone tenerse a uno por objeto, reconocerse como el límite que la propia voluntad se da a sí misma. Esto es, permanecer idéntico en la separación, afirmarse como uno en la negación de la unidad. Entonces, no se trata de hacer de la voluntad libre aquello que rechaza de sí las figuras que tome el Yo — según las palabras de Hegel la voluntad libre tiene necesariamente la forma de un Yo- sino de la existencia de ese Yo en tanto determinado (Hegel, 2009: 46). La conciencia libre es, de este modo, aquella que sabe de sus propias determinaciones, que se sabe determinada y que encuentra su libertad en la determinación, al tomarla por objeto. Así, Hegel desarrolla una forma de conocimiento que no opone como figuras exteriores determinación y libertad (Taylor, 2010: 267). Dice:

La independencia de lo uno existente-para-sí, impulsada hasta su cumbre, es la independencia abstracta, formal, que se destruye a sí misma, es el error sumo y más obstinado, que se toma [a sí mismo] por la verdad más alta —manifestándose en formas más concretas, como libertad abstracta, como el puro yo, y por lo tanto luego como el mal. Es esta libertad que se equivoca hasta el punto de poner su esencia en esta abstracción y se lisonjea de alcanzarse en su pureza dentro de este ser-en-lo-de-sí misma. Esta independencia constituye de manera más determinada el error de considerar como negativo lo que es su propia esencia y mantenerse a sí mismo como negativo contra él (...) La reconciliación consiste en el reconocimiento de que aquello, contra lo cual se dirige el comportamiento negativo, es más bien lo que constituye su propia esencia; y [tal reconciliación] sólo se da como un desistir de la negatividad de su serpara-sí en lugar de mantenerse firme en ella (Hegel, 1982 TI: 220).

Entonces, la esencia de la libertad no consiste en que el Yo se independice de toda figura y se conserve en su pureza más allá de toda determinación ${ }^{6}$. Por el contrario, dice Hegel, la esencia del Yo radica en mantenerse firme en aquello contra lo cual este Yo se quiere afirmar, en las determinaciones de este Yo. Este tránsito desde la conciencia abstracta a una que se reconoce en su propia objetividad, es el devenir de la autoconciencia. Puede leerse el famoso pasaje de la Fenomenología del Espíritu, que citamos en extenso:

Solamente en estos tres momentos se ha cumplido el concepto de la autoconciencia de sí: a) el puro yo no diferenciado de su primer objeto inmediato b) Pero esta inmediatez es ella misma mediación absoluta, sólo es como superación del objeto independiente, o es la apetencia. La satisfacción de la apetencia es, ciertamente, la

${ }^{6}$ Hegel critica esta apariencia, al plantear el carácter abstracto de aquel modo de concebir la libertad. Siguiendo a Iñigo Carrera, decimos que esta libertad abstracta es una forma de conciencia necesaria bajo el modo de producción capitalista, ya que ante los productores de mercancías la independencia de su propia voluntad aparece chocando con la de los demás. En la circulación, así, los productores de mercancías se enfrentan a sus propias relaciones sociales justamente bajo el modo que Hegel critica; se ven a sí mismos de forma abstractamente libre. 
reflexión de la autoconciencia en sí misma o la certeza que ha devenido verdad. c) Pero la verdad de esta certeza es, más bien la reflexión duplicada, la duplicación de la autoconciencia. Es un objeto para la conciencia, que pone en sí mismo su ser otro o la diferencia como algo nulo, siendo así independiente (...) En cuanto una autoconciencia es el objeto, éste es tanto yo como objeto (Hegel, 2006: 112-113).

La autoconciencia sintetiza así este movimiento genérico de la conciencia en la cual ella deviene lo que es al negar sus sucesivas figuras. En otras palabras, la autoconciencia muestra cómo la conciencia se realiza negando sus propias negaciones, afirmándose en ellas.

Para Hegel toda determinación traspasa por su propio movimiento a otra, por lo cual la negatividad es propia de todo lo real, sin ser exclusiva del espíritu. Sin embargo, solo con la ciencia del espíritu, forma desplegada del propio espíritu, es decir, con su propia filosofía, el movimiento genérico de negación de la propia negación se torna consciente (Hegel, 1997: 602). Escribe en el Prólogo a la Fenomenología del Espíritu:

Sólo lo espiritual es lo real; es la esencia o el ser en sí, lo que se mantiene y lo determinado - el ser otro y el ser para sí- y lo que permanece en sí mismo en esta determinabilidad o en su ser fuera de sí o es en y para sí. Pero este ser en y para sí es primeramente para nosotros o en sí, es la sustancia espiritual. Y tiene que ser esto también para sí mismo, tiene que ser el saber de lo espiritual y el saber de sí mismo como espíritu, es decir, tiene que ser como objeto y tiene que serlo, asimismo, de modo inmediato, en cuanto objeto superado, reflejado en sí. (...) El espíritu que se sabe desarrollado así como espíritu es la ciencia. Esta es la realidad de ese espíritu y el reino que el espíritu se construye en su propio elemento (Hegel, 2006: 19).

$\mathrm{Al}$ movimiento que en la ciencia deviene consciente, Hegel lo denomina permanecer en sí en el ser fuera de sí y lo considera la determinación más general de lo real, el corazón del movimiento dialéctico ${ }^{7}$. Aquí reside, a nuestro modo de ver, el núcleo racional de su filosofía: el descubrimiento de la afirmación mediante la propia negación como la determinación más sim-

${ }^{7}$ Hegel hace del movimiento del pensamiento lo propio de todo lo que es, de todo lo real. Por eso se trata de un conocimiento, en esa medida, objetivo, capaz de cuenta de sus determinaciones más abstractas (Hegel, 1982 TII: 267). Como a Hegel no se le aparece que el ser social determina a la conciencia, no necesita preguntarse qué ser social es el que produce la conciencia dialéctica. Sin embargo, Hegel demuestra la necesidad de que el pensamiento se desarrolle hasta reconocer su propio movimiento dialéctico. Realiza tanto una filosofía de la historia como una historia de la filosofía, en la que se encarga de mostrar el progreso del pensamiento hasta llegar a su propio sistema filosófico. En este sentido, Hegel desenvuelve la necesidad de cada figura que toma el pensamiento y pone esta necesidad en las propias contradicciones en las que ingresa consigo mismo. Nuestro punto es que por tratar al pensamiento como un sujeto que se pone en marcha a sí mismo, Hegel no se interroga por su determinación. 
ple de todo lo real (Iñigo Carrera, 2004: 229-230). De modo que este punto, central, es el que, a nuestro modo de ver, Marx retoma de su filosofía. Sin embargo, ante el desarrollo que acabamos de hacer cabe interrogarse: ¿por qué si la dialéctica es el movimiento de todo lo real, solo el capitalismo produce la conciencia acerca de ella? ¿Por qué solo con el capitalismo aparece la figura de Hegel, que sintetiza las determinaciones generales de la dialéctica? En el siguiente apartado desplegaremos los elementos centrales de esta respuesta.

\section{La libertad como forma de la enajenación}

La conciencia, afirmamos, es el atributo humano que se encarga de organizar la descarga individual del trabajo social. Bajo el modo de producción capitalista, la organización del trabajo enajena a la conciencia de los seres humanos de las potencias sociales de su trabajo. Se trata, en resumidas cuentas, de una conciencia, que es un atributo humano, puesta como atributo de una relación social objetivada (Iñigo Carrera, 2012: 76). Pero, si el capital hace que las relaciones sociales con las que los individuos producen su vida se sustantiven y presenten, entonces, como una cosa exterior que los domina, vale reiterar la pregunta con la que cerramos el apartado anterior: ¿Por qué solo bajo la sociedad capitalista aparece la figura de Hegel, que sintetiza las determinaciones generales de la dialéctica? La respuesta radica, desde nuestra perspectiva, en que el modo de producción capitalista es el primero en la historia que extiende la libertad como relación social general. Los modos de producción anteriores se basaban en relaciones de dependencia personal, en vínculos directos en los cuales ciertos miembros de la sociedad poseían a título personal la capacidad para organizar el trabajo de los otros. En contraposición, respecto de la conciencia libre del productor de mercancías, escribe Iñigo Carrera:

El acto en que su conciencia y voluntad dominan por sí las determinaciones de su trabajo individual afirmándolo como un individuo libre, es el acto en que su conciencia y voluntad dan cuerpo a su impotencia para dominar las determinaciones sociales de su trabajo, realizando su falta absoluta de libertad respecto de ellas (...) Su conciencia y voluntad libres son la forma de realizarse su conciencia enajenada. El productor necesita aplicar los atributos de su personalidad humana, su conciencia y voluntad, como si fueran atributos de su mercancía. Tiene que actuar como personificación de su mercancía (Iñigo Carrera, 2007: 59).

La conciencia del productor de mercancías es la primera en la historia de la humanidad que es libre porque está enajenada. El productor se afirma 
como libre al organizar consciente y voluntariamente su trabajo individual mientras que carece de libertad respecto de su ser social. Puesto de otro modo, actúa como persona cuando personifica una cosa exterior a él, una forma objetivada que determina su conciencia como una enajenada. Así, la conciencia del productor de mercancías tiene en sí misma un movimiento en el que se comporta como libre en el mismo momento en que se determina por una cosa que aparece como exterior.

En las sociedades basadas en relaciones de dependencia personal, el individuo tenía su vínculo puesto en una persona, por lo cual no se le aparecía, al momento de realizar su ser genérico, esto es, de trabajar, que estaba privado de relaciones con los otros. Jamás podía presentársele que era libre frente a una persona determinada, justamente porque el atributo social se llevaba personalmente. Por el contrario, bajo el modo de producción capitalista los individuos son libres porque su conciencia y voluntad están puesta al servicio de una forma objetivada que porta el vínculo social con los demás, que se pone en marcha a sí misma y que priva al productor, al momento de trabajar, de toda relación social con los otros. Entonces, cuando el individuo ve a la mercancía, tiene frente a sí el ejercicio de su libertad contrapuesto a su propia persona. Esto es, se enfrenta a su conciencia enajenada. En otros términos, el individuo tiene delante de sí a su propia libertad como una determinación exterior, que no le pertenece. Esto, decimos, es lo que no le ocurre a un individuo cuya relación social general está organizada por vínculos de dependencia personal, puesto que no puede enfrentarse a su ser social como el resultado de su arbitrio, y por lo tanto no puede mirar su determinación por el ser social como contrapuesta a su persona. En suma, solo un individuo que tiene como atributo productivo la libertad tiene la posibilidad de preguntarse por la determinación de su conciencia por una relación social.

Pues bien, nuestro punto es que el capitalismo engendra el reconocimiento del movimiento dialéctico de todo lo real porque enfrenta a la conciencia a esta condición. Solo la conciencia enajenada en la mercancía puede ver su libertad como contrapuesta a sí misma; puede rechazarse de sí al ponerse como personificación y afirmarse en este acto como libre. Es decir, solo la conciencia enajenada puede enfrentarse a sí y afirmarse mediante su negación en este desdoblamiento. Por eso el capital engendra entre sus formas de conciencia aquella que reconoce esta condición. Así, solo cuando un ser social específico enfrenta a la conciencia a esta condición suya el conocimiento dialéctico aparece sintetizado en sus formas generales. El núcleo racional de la dialéctica hegeliana consiste, para nosotros, en haber puesto al descubierto este movimiento de afirmación mediante la propia negación. 
Respecto de la envoltura mística de la dialéctica, esta se debe a que en manos de Hegel la afirmación mediante la propia negación es el movimiento que preside el desarrollo del pensamiento puesto en marcha por sí mismo. Esto es, abstraído de toda determinación por el ser social. Ahora bien, esta abstracción del pensamiento de sus determinaciones materiales es resultado de la propia forma enajenada en la que se organiza el trabajo social. Dice Marx:

El hombre extrañado de sí mismo es también el pensador extrañado de su esencia, es decir, de la esencia natural y humana. Sus pensamientos son, por ello, espíritus que viven fuera de la Naturaleza y del hombre. En su Lógica, Hegel ha encerrado juntos todos estos espíritus y ha comprendido a cada uno de ellos, en primer lugar, como negación, es decir, como enajenación del pensar humano, después como negación de la negación, es decir, como superación de esta enajenación, como verdadera exteriorización del pensar humano; pero, presa ella misma aun en el extrañamiento, esta negación de la negación es, en parte, la restauración de estos espíritus en el extrañamiento, en parte la fijación en el último acto, el relacionarse-consigo-mismos en la enajenación como existencia verdadera de estos espíritus. (Es decir, Hegel coloca en lugar de aquella abstracción fija el acto de la abstracción que gira en torno a sí mismo (...)) (Marx, 2001: 205-206).

En línea con el argumento de Marx, decimos que Hegel hace girar a la abstracción sobre sí misma puesto que se trata del pensamiento extrañado del ser humano, su sujeto. Ahora bien, Marx indica que este pensamiento extrañado es el de la humanidad extrañada (entfremdete). Esto implica, a nuestro modo de ver, que es la propia enajenación de la humanidad en el producto de su trabajo la que produce el pensamiento extrañado, exterior a ella, puesto por Hegel como su propio motor, como un pensamiento que gira sobre sí mismo y fuera, por lo tanto, de las relaciones sociales con las que la humanidad produce su vida. Se trata, para nosotros, del pensamiento puesto en marcha por sí mismo, enajenado, como resultado de la enajenación producida por la organización del trabajo social por el capital.

Así, Hegel toma la autonomización de la organización del trabajo social, que se pone en marcha a sí misma con el objeto de producir valor, es decir, más de sí, como si fuese una de la forma humana encargada de organizar dicho trabajo, la conciencia. En vez de ver cómo la necesidad genérica de reproducir la vida a través del trabajo toma la forma de una relación social enajenada, que hace a la conciencia una igualmente enajenada, concibe al carácter automático de la relación social como si se tratara de la autonomización de la conciencia, su puesta en marcha por sí misma. En tanto la conciencia es la encargada de organizar el trabajo social, la organización autónoma de este trabajo por el capital es pensada por Hegel como la 
autonomización de la conciencia de sus determinaciones materiales. Creemos que las siguientes palabras de Marx van en este sentido: "La lógica es el dinero del espíritu, el valor pensado; especulativo, del hombre y de la naturaleza; su esencia que se ha hecho totalmente indiferente a toda determinación real y es, por tanto, irreal; es el pensamiento enajenado que por ello hace abstracción de la naturaleza y del hombre real; el pensamiento abstracto" (Marx, 2001: 188).

La dialéctica de Hegel hace abstracción de las relaciones sociales que la humanidad traba para producir su vida. Este pensamiento abstracto, enajenado, responde, según Marx, a que el propio ser real humano está enajenado. Lo que nosotros sostenemos aquí es que esa abstracción del pensamiento de su sujeto ocurre porque el sujeto de la vida social bajo el modo de producción capitalista es uno automático, es el valor en proceso de valorización. Este sujeto, que es la relación social materializada en el producto del trabajo, abre el proceso de producción social con el objeto de producir más de sí. Se trata, entonces, de un proceso automático, que se pone en marcha a sí mismo. Hegel a nuestro modo de ver, traspone este proceso a la conciencia, como si ésta tuviese la capacidad de poner en marcha su propio movimiento, cuando, como vimos más arriba, se trata del atributo humano que organiza la descarga del trabajo social. Entonces, el carácter automático de la relación social enajenada es la que determina el carácter enajenado de la conciencia. Hegel presenta a esta forma enajenada como la capacidad del pensamiento de ponerse en marcha a sí mismo. Dice Marx: "El extrañamiento de la conciencia no es considerado como expresión (expresión que se refleja en el saber y el pensar) del extrañamiento real de la humana esencia. El extrañamiento verdadero, que se manifiesta como real, no es, por el contrario, según su más íntima y escondida esencia (que sólo la Filosofía saca a la luz) otra cosa que el fenómeno del extrañamiento de la esencia humana real, de la autoconciencia" (Marx, 2001: 193).

En palabras de Marx, el extrañamiento de la conciencia no es considerado como expresión del extrañamiento real de la humanidad. De este modo, Hegel no se enfrenta a que la conciencia esté enajenada en la relación social vuelta automática. Por el contrario, le adjudica al pensamiento la capacidad de "girar sobre sí", de ponerse en marcha a sí mismo, de ser, a nuestro modo de ver, automático. Esto es, Hegel le adjudica al pensamiento, por desconocer sus determinaciones materiales, el carácter que tiene el capital como sujeto automático de la organización de la vida social. En este carácter extrañado del ser real enajenado reside el aspecto mistificador de la dialéctica hegeliana. Recojamos, entonces, la necesidad que encuentra Marx 
de invertirla. Escribe: "La existencia de los predicados es el sujeto: por lo tanto el sujeto es la existencia de la subjetividad, etc. Hegel adjudica una existencia independiente a los predicados, a los objetos, pero separándolos de su verdadera independencia, de su sujeto. El sujeto real aparece después, como resultado, en tanto que hay que partir del sujeto real y considerar su objetivación" (Marx, 1970: 33).

La dialéctica de Hegel pone al pensamiento como el sujeto de la realidad existente y aquel que la determina. Dicho de otro modo, hace del pensamiento el sujeto que se pone a sí mismo en lo otro de él (Hegel, 1982 TII: 479). No obstante lo cual, Hegel presenta de modo estilizado el movimiento de afirmarse a través de la propia negación como la determinación fundamental de todo lo real. Este movimiento es el que caracteriza, de modo general, a la dialéctica (Marx, 2001: 186). De allí su núcleo racional.

\section{Conclusiones}

Comenzamos nuestro trabajo mostrando que bajo el modo de producción capitalista el producto del trabajo porta la organización de la producción y el consumo. Se transforma así en el sujeto de la vida social. Este sujeto encierra un tipo de unidad mediata entre la producción y el consumo: se trata de una unidad portada en la realización de los trabajos útiles concretos de forma privada e independiente.

Indicamos, posteriormente, que el capitalismo hace a la conciencia enfrentarse a su dialéctica interna porque a los trabajadores doblemente libres se les presenta su ser social, su propio ser, como algo ajeno que los domina y en el que a la vez se afirman como libres. Esto es, que son libres porque se encuentran enajenados en los atributos sociales de su trabajo. Aquí reside entonces, en palabras de Marx, la base que permite a Hegel desarrollar el núcleo racional de la dialéctica: el descubrimiento y presentación estilizada del afirmarse mediante la propia negación como la determinación más simple de lo real.

Respecto del carácter mistificado de esta dialéctica, sostuvimos que consistía en tomar al pensamiento como sujeto de su propio desarrollo, como un elemento que se pone en marcha a sí mismo. En este movimiento, siguiendo a Marx, afirmamos que Hegel le adjudicaba "una existencia independiente a los predicados (...) pero separándolos de su verdadera independencia, de su sujeto" (Marx, 1970: 33), esto es, que Hegel tomaba al pensamiento como extrañado del ser humano, justamente porque el ser 
humano se encuentra enajenado en la forma en la que organiza la reproducción de su propia vida genérica. De este modo, dijimos que Hegel expresaba la enajenación de la conciencia del productor de mercancías al suponer que el pensamiento se pone en marcha a sí mismo, cuando se trata de la forma en la que cada individuo organiza su trabajo individual como órgano del social. De ahí que Marx encontrara la necesidad de invertir la dialéctica, para mostrar su núcleo racional.

Tras haber avanzado este resultado, nos resta, por último, señalar qué perspectivas arroja respecto de la literatura especializada en la que enmarcamos nuestro trabajo. Como dijimos, dentro del campo de la Dialéctica Sistemática, la tesis de la homología entre el movimiento de lo Absoluto hegeliano y del capital concitó nuestra atención, toda vez que la noción de homología situaba la centralidad del movimiento del capital como sujeto enajenado, al compararlo con aquel propio de lo Absoluto.

En el marco de la tesis de la homología, recuperamos los dos planteamientos que consideramos más acabados. El primero, el de uno de sus impulsores fundamentales, Lucio Colletti; luego, el de Christopher Arthur, parte de los autores que conforman el enfoque de la Dialéctica Sistemática. En el caso de Colletti, la tesis de la homología — que, cabe recordar, él no formula en esos términos pero que Bellofiore señala como uno de sus antecedentes (2014) - deriva en un rechazo in toto de la dialéctica. Justamente porque ésta refleja el movimiento de un sujeto invertido, el capital, es que se trata de un método intrínsecamente idealista. De modo que Collettí rechaza toda pertinencia del descubrimiento de Hegel, en tanto le adjudica la conversión de lo finito en una forma de una existencia infinita, que Colleti asocia al ámbito ideal. Dice Colletti refiriéndose a Hegel: "En la práctica, esa innovación significa lo siguiente: ya no se dice solo que lo finito no tiene verdadera realidad (...) sino que se añade que lo finito tiene como esencia y fundamento suyo lo 'otro' de sí mismo, es decir, lo infinito, lo inmaterial, el pensamiento.” (Colletti, 1977: 15) Como Colletti impugna a Hegel por asociar dialéctica e idealismo, la crítica al segundo se lleva consigo a la primera, lo cual redunda en que Colletti rechaza aquello que nosotros indicamos como núcleo racional de la dialéctica hegeliana: el descubrimiento de que toda forma lleva en sí la necesidad de su superación, movimiento que resumimos como afirmación mediante la propia negación. Así, la tesis de la homología conduce a Colletti a rechazar al pensamiento de Hegel en su totalidad, lo cual soslaya, desde nuestro punto de vista, la enorme potencia que encierra su dialéctica. 
Arthur, mientras tanto, también encuentra una homología entre el modo en el que discurre lo Absoluto para Hegel y el comportamiento del capital en tanto sujeto de la vida social bajo el modo de producción capitalista. El núcleo racional de la dialéctica estaría así representado por su capacidad para sintetizar bajo una forma lógica el movimiento específico del capital. Sin embargo, nuestra principal objeción es que el propio Arthur limita la validez de esta homología, toda vez que concibe al capital como un protosujeto que debe comprobar esta condición al imponerse frente la resistencia de la clase obrera. Por lo tanto, el capital adolece de aquello que en la filosofía hegeliana hace sujeto a lo Absoluto: la capacidad para actualizar y reproducir sus propias condiciones de existencia (Arthur, 2004: 106), ya que la reproducción de sus propios presupuestos queda supeditada a que consiga doblegar la resistencia obrera. De modo que en los propios términos de Arthur, la homología entre Absoluto y capital, que concentraría el aporte que realiza Hegel a la crítica de la economía política, resulta parcial y, así, desde nuestra perspectiva, queda comprometida la vinculación formulada por el propio autor. De ahí la necesidad de plantearla en otro terreno.

En nuestra revisión de la literatura pertinente recuperamos brevemente los señalamientos realizados por Tony Smith, en tanto se trata de un autor que expone de modo estilizado la otra de las vertientes que confluyen en la Dialéctica Sistemática. Sin embargo, como Smith no encuentra diferencias sustantivas entre los enfoques de Marx y de Hegel, su planteamiento no hace lugar a la necesidad que Marx encuentra de invertir la dialéctica hegeliana. Esto es, como Smith enfatiza que Marx se apropia de la reconstrucción categorial de las determinaciones más simples de lo real realizada por Hegel, su planteamiento no permite problematizar cuál es el sujeto del movimiento dialéctico en el caso de uno y de otro autor. Nuestro trabajo procuró mostrar que la mistificación que Marx encuentra en la filosofía de Hegel obedece a que para este último el pensamiento es el sujeto de su propio despliegue, en el que se pone en marcha a sí mismo. De ahí entonces la necesidad de invertir la dialéctica, lo cual implica reconocer al verdadero sujeto bajo la sociedad capitalista; no se trata de la conciencia del productor de mercancías o la genéricamente humana, sino del capital. Así como el capital es una forma autónoma de organizarse el trabajo social, cuyo objeto es autoproducirse, así a Hegel se le presenta que la portadora de esta organización, la conciencia, es autónoma, es decir, se pone a sí misma. De ahí que Hegel atribuya a la conciencia aquello que es potestad del producto del trabajo en el que está enajenada y, en esa medida, niegue la necesidad de superar esa forma de conciencia. Hegel, por investir a la conciencia con el 
atributo del cual carece bajo nuestra relación social general, pierde de vista la necesidad de preguntarse por la determinación histórica de esta forma de conciencia y, por tanto, por las condiciones que engendra esta relación social de cara a su ruina. Desarrolla las formas generales de la dialéctica y al mismo tiempo le adjudica este movimiento a un predicado que presenta separado del verdadero sujeto de la sociedad actual. Por eso, pierde de vista que este sujeto alberga la necesidad de ser superado.

\section{Bibliografía}

Albritton, R. y Simoulidis, J. (eds.), New Dialectics and Political Economy, Basingstoke, Palgrave Macmillan, 2003.

Arthur, C., The new dialectic and Marx's Capital, Leiden, Brill, 2004.

Arthur, C., "De la crítica de Hegel a la crítica de capital”. En Robles Báez, M. (comp.) Dialéctica y Capital. Elementos para una reconstrucción de la crítica de la economía política, México, Universidad Autónoma Metropolitana, 2005, pp. 229-256.

Arthur, C. \& Reuten, G., The Circulation of Capital: Essays on Volume II, Basingstoke, Macmillan Press, 1998.

Bellofiore, R., "Lost in Translation: Once Again on the Marx-Hegel Connection”. En Moseley, F. \& Smith, T. (eds.), Marx's Capital and Hegel's Logic. A Reexamination, Leiden, Brill, 2014, pp. 164-188.

Caligaris, G. y Starosta, G., Trabajo, valor y capital. Bernal, Universidad de Quilmes, 2018.

Colletti, L., El marxismo y Hegel, México, Grijalbo, 1975.

Colletti, L., La dialéctica de la materia en Hegel y el materialismo dialéctico. México, Grijalbo, 1977.

Colletti, L., La superación de la ideología, Madrid, Cátedra, 1982.

Fineschi, R., "'Capital in General' and 'Competition' in the Making of Capital: The German Debate”, Science \& Society, vol. 73, N¹, 2009, pp. 54-76.

Hegel, G. W. F., Ciencia de la lógica, Buenos Aires, Ediciones Solar, 1982.

Hegel, G. W. F., Enciclopedia de las Ciencias Filosóficas, Madrid, Alianza, 1997.

Hegel, G. W. F., Fenomenología del espíritu, México, Fondo de Cultura Económica, 2006.

Hegel, G. W. F., Filosofía del derecho, Buenos Aires, Claridad, 2009.

Iñigo Carrera, J., El capital: razón histórica, sujeto revolucionario y conciencia, Buenos Aires, Ediciones Cooperativas, 2004. 
Iñigo Carrera, J., Conocer el capital hoy. Usar críticamente "El Capital". Volumen 1, La mercancía, o la conciencia libre como forma de la conciencia enajenada, Buenos Aires, Imago Mundi, 2007.

Iñigo Carrera, J., "Dialectics on Its Feet, or the Form of the Consciousness of the Working Class as Historical Subject”. En F. Moseley \& T. Smith (eds.), Marx's Capital and Hegel's Logic, Boston, Brill, 2012. p. 64-88.

Marx, K., Crítica de la filosofía del Estado de Hegel, México, Grijalbo, 1970.

Marx, K., El capital, Tomo I, vol. 1, México, Siglo XXI Editores, 1999.

Marx, K., Manuscritos Económico Filosóficos. Edición preparada por Juan

R. Fajardo para el MIA, 2001. Disponible en, https,//www.marxists.org/ espanol/me/1840s/manuscritos/ [Consultado el 27 de Marzo de 2020]

Marx, K y Engels, F., La ideología alemana, Barcelona, Grijalbo, 1970.

Marx, K y Engels, F., Werke, Band 13, 7, Dietz Verlag, Berlin/DDR, 1971. p. 7-11.

Marx, K y Engels, F., Obras Escogidas. Vol I, Moscú, Progreso, 1976.

Moseley, F., Capital in General and Competition in Volume 3 of Capital: The Quantitative Dimension. South Hadley, Mount Holyoke College, 2005.

Moseley, F. \& Campbell, M. (eds.), New Investigations of Marx's Method, New Jersey, Humanities Press International, 1997.

Moseley, F \& Smith, T. (eds.), Hegel's Logic and Marx's Capital, Leiden, Brill, 2014.

Murray, P., "The Necessity of Money, How Hegel Helped Marx to Surpass Ricardo's Theory of Value". En Moseley, F. (ed.), Marx's Method in Capital. A Reexamination, Atlantic Highlands, Humanity Press, 1993. p. 37-62. .

Postone, M., Tiempo, trabajo y dominación social. Madrid, Marcial Pons, 2006.

Reuten, G. \& Williams, M., Value-form, and the state. The tendencies of accumulation and the determination of economic poilicy in capitalist society. Londres, Routledge, 1989.

Robles Báez, M., Dialéctica y Capital. Elementos para una reconstrucción de la crítica de la economía política, México, Universidad Autónoma Metropolitana, 2005.

Robles Báez, M., Marx: lógica y capital. La dialéctica de la tasa de ganancia y la forma precio, Ciudad de México, Universidad Autónoma Metropolitana, 2011.

Smith, T. The Logic of Marx's Capital. Replies to hegelian criticisms, Albany, SUNY Press. 1990. 
Starosta, G., "Fetichismo y revolución en la teoría marxista contemporánea: una evaluación crítica de la Neue Marx-Lektüre y el Marxismo Abierto en clave metodológica", Izquierdas, 37 (diciembre), 2017, pp. 162-190.

Taylor, Ch., Hegel, México, Antrhopos, 2010. 